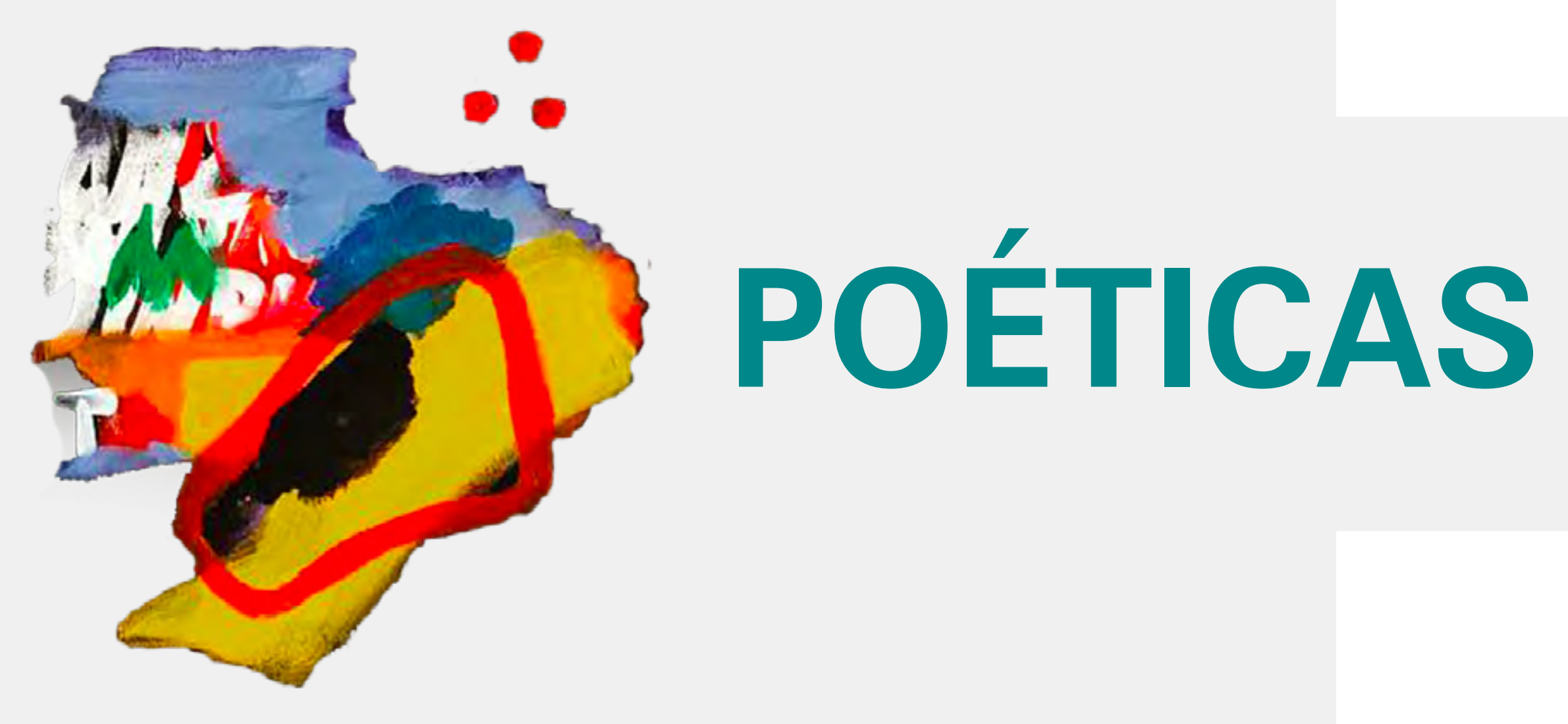




\section{MICRO HISTÓRIAS. APOCALIPSES COTIDIANOS.}

Vários

CURADORIA:

Melissa de Sá

Revista Mafagafo
Recorte da criação brasileira de literatura digital no Twitter, que desafiou escritores a publicarem seu microconto apocalíptico com a hashtag \#emtese. A seleção dos melhores foi feita pela editora desse dossiê, Melissa de Sá, e por Janayna Bianchi, editora da revista Mafagafo.
Revista Mafagafo: Ninguém nunca viu um Mafagafo, mas todo mundo sabe que é um bicho que mora num ninho e tá sempre cheio de filhotinhos. E, desde 2018, quem escreve fantasia e ficção científica sabe que Mafagafo é também uma publicação digital de contos e noveletas criada com foco no processo editorial o material enviado para submissão é a matéria-prima e a revista publicada é o produto final. Nossa proposta é trabalhar no que fica entre um e outro - o processo editorial sério, com o preparo cuidadoso do texto através do trabalho em equipe.

mafagaforevista.com.br 

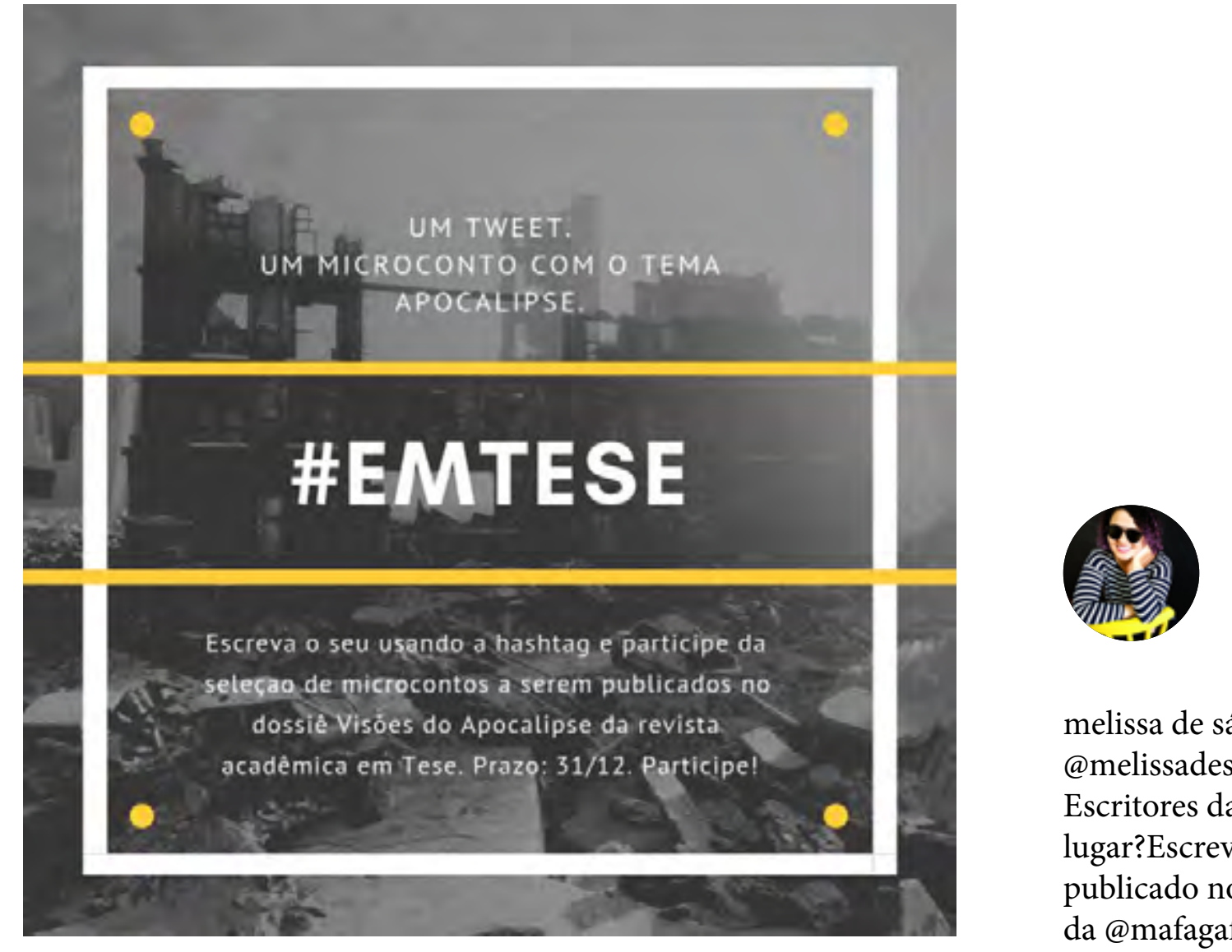

melissa de sá

@melissadesa

Escritores da timeline! Bora mostrar que lugar de literatura BR é em todo

lugar?Escreva seu microconto de temática apocalíptica com hashtag \#emtese e seja

lugar?Escreva seu microconto de temática apocalíptica com hashtag \#emtese e seja
publicado no dossiê de uma revista acadêmica! Selecionaremos os melhores com apoio da @mafagaforevista e @RevistaTrasgo ! 
Rafael Palma

@rpalma_

O apocalipse chegou, sorrateiro e faminto. Se alimentou de conflitos, arrotou diferenças.

Dividiu as pessoas até que elas esquecessem o que tinham em comum. Ninguém viu o fim

chegar porque ninguém olhou para dentro de si. O mundo acabou por inteiro, um ser humano

por vez. \#emtese 
$={ }_{0}^{3}$

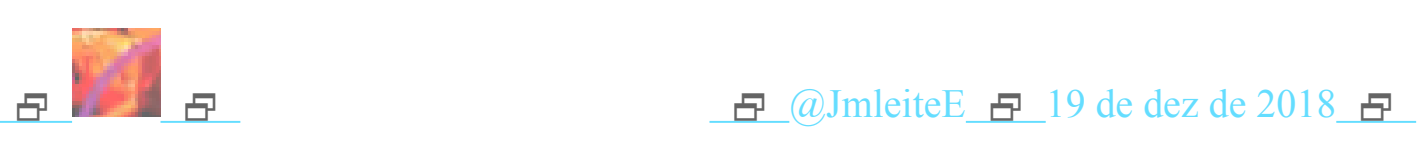

무 19 de dez de 2018 무

무 19 de dez de 2018 무
-

${ }^{2}$.

ㅁ@‥JleiteE
모.JmleiteE。 19 de dez de 2018 무 


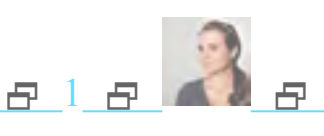
무의

${ }_{8}$.

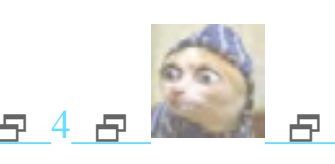

모sanduiche_papel_무 13 de dez de 2018 무

모@coadjuvando_무 13 de dez de 2018 모 @fuinhamagra_a 18 de dez de 2018

.
• (Q)eumateimufasa o 12 de dez de 2018 •

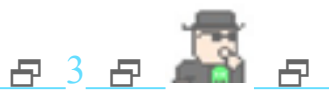

모 @TheRandomOne
무 11 de dez de 2018 무

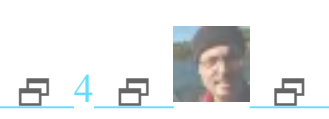

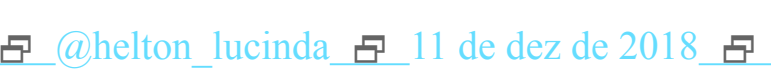

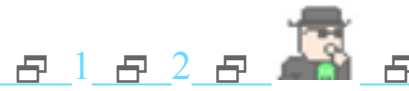

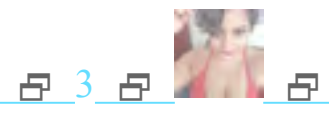

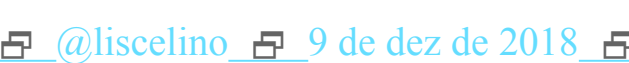

\section{(8)}

Madame Satã

@witchgianni_

Atenção: esta mensagem do futuro se autodestruirá em segundos. A frequência pela qual estes

caracteres viajam não nos permite enviar além. Há um motivo pelo qual esta hecatombe se

abateu a nível mundial, mas ainda há uma forma de impedir. O que vocês necessitam fazer é

abateu

\#emtese 


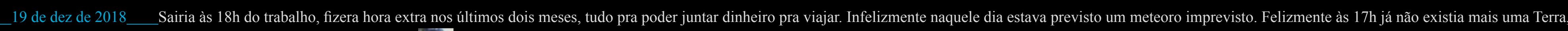

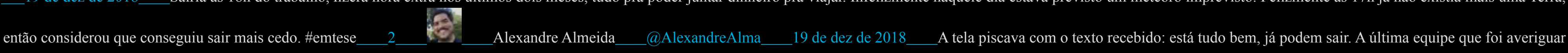

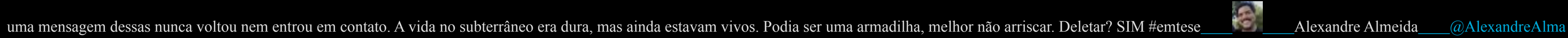

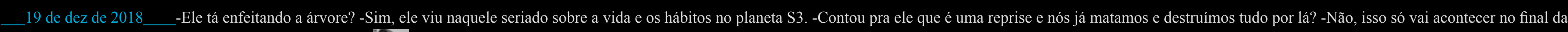
segunda temporada. Até lá ele já perdeu o interesse. \#emtese

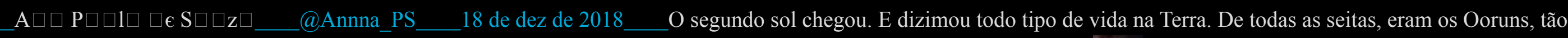
ridicularizados por todos, que estavam certos, afinal. Todos cantavam a música, ninguém acreditava. A vida ardia, mas todas as explicações já haviam sido dadas. Você ouviu? \#emtese

takoDANA@dana aoi_18 de dez

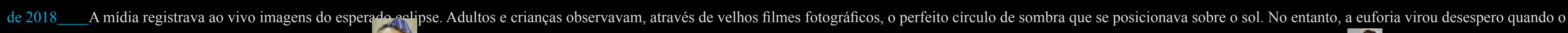
céu para sempre se tornou escuridão. \#emtese___ _ _ Felipe Rodrigues__@fuinhamagra___ 18 de dez de 2018___Bom dia twitter, esse é o primeiro dia do resto de sua vi... \#emtese

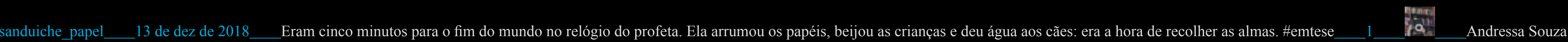

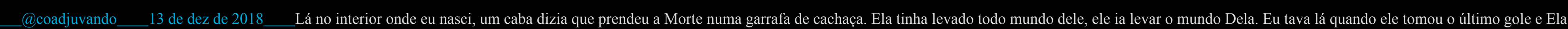

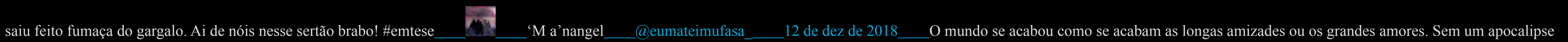

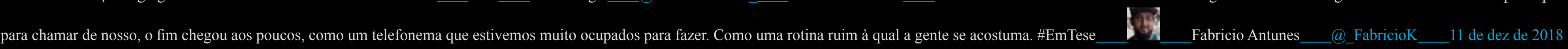

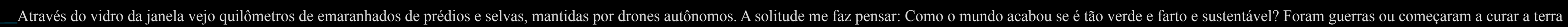
tarde demais para aproveitar? \#emtese fake geek boy___@TheRandomOne

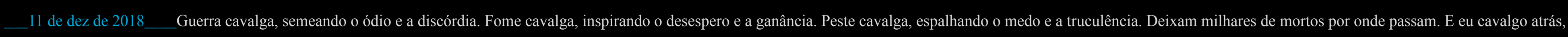

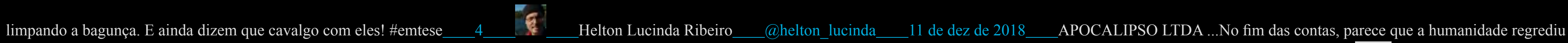

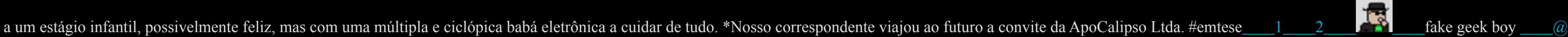

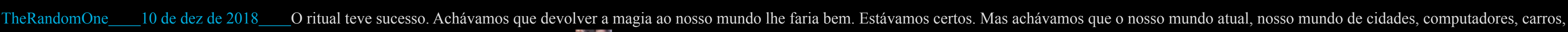
celulares, continuaria existindo, junto com a magia. Estávamos errados. \#emtese __ 3

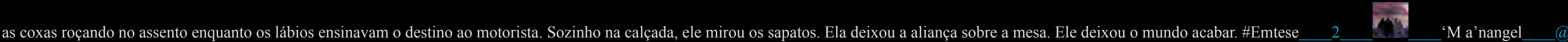

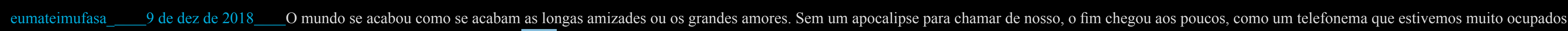
para fazer. Como uma rotina ruim à qual a gente se acostuma. \#EmTese 


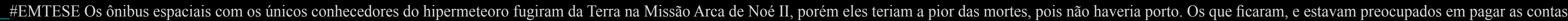

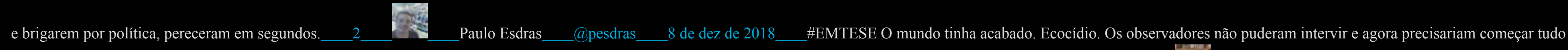
novamente. 350 mil anos destruindo o próprio ambiente, depois dos dinossauros, o "Projeto Humanos" foi um desastre. Do que sobrou na Terra, agora será "projeto baratas".

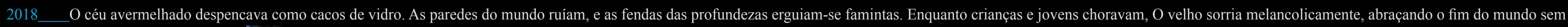
nenhum arrependimento. \#emtese

- MAXON CARTER TÁ NAAMAZON@oltonMoraes 8 de dez de 2018 Ele era feito de fogo. Não só disso, cla como o fogo, ele queimava, virava em cinzas, e em cinzas o mundo se transformava. E ali, em seu inferno intrapessoal, queimavam, sem tempo de escapar, o pessoal. \#EmTese

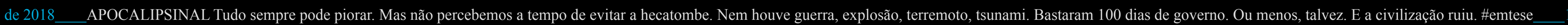
8 is

verde que avistara. Mas quando tentou toca-la, a imagem se desfez. Era mais uma miragem. Mais uma... dentre milhares. 17. decretou: Não teremos mais filhos, não deixaremos a ninguém o legado de nossa miséria! E citando Machado, anunciou o último suspiro dos humanos e a grande esperança da Terra. \#emtese O chefe da Associação Médica Mundial em tom solene

\title{
MICRO HISTÓRIAS. APOCALIPSES COTIDIANOS.
}

\author{
a Clique para ler a hashtag no Twitter.
}

